Review Article

\title{
A Review on Novel Targets for Osteoarthritis Therapy
}

\author{
Neha Singh, Vivek Srivastava*, Alok Shiomurti Tripathi, Himani Awasthi \\ Amity Institute of Pharmacy, Amity University, Lucknow Campus, India. \\ *Corresponding author's E-mail: vsrivastava1@lko.amity.edu
}

Received: 18-12-2020; Revised: 12-02-2021; Accepted: 21-02-2021; Published on: 20-03-2021.

\begin{abstract}
Osteoarthritis $(O A)$ is a progressive disease that affects $25 \%$ of the world's population over fifty years of age. It is a long-lasting disease of the synovial joints, primarily the hip and knee. The main pathologies are degradation of the articular cartilage and changes to the subchondral bone. There are various target of OA Proteinase-activated Receptor-2, BRD4 has dual effects on the HMGB1 and NF-KB signaling pathways it demonstrated that OA also has an inflammatory component. BRD4, a member of the Bromodomain and ExtraTerminal Domain family, has emerged as an important regulator of some chronic inflammatory diseases. JQ1, an antagonist of BRD4, modulates transcription of several genes. BRD4 is up-regulated in articular cartilage of OA. Novel hyaluronic acid-chitosan nanoparticles as non-viral gene transporter vectors targeting osteoarthritis. The nucleotide-binding and oligomerization domain-like receptor holding protein 3 (NLRP3) inflammasome has been implicated in the pathogenesis of a numeral of arthritic disorders, producing proinflammatory cytokines and degradative enzymes like Interleukin-1 beta (IL-1b), Tumor necrosis factor alpha (TNF-a) and Matrix metalloproteinase-3 (MMP-3) which drive cartilage degeneration and synovial inflammation. Some novel and latent therapies are used to treatment of osteoarthritis like Pharmacological therapies, Regenerative therapies, Mesenchymal stem cell therapy. Mesenchymal stem cells (MSCs) due to their multi-lineage potential, immunosuppressive activities, and relative ease of growth in culture, have attracted attentions for clinical use. Low level laser therapy, Cytokines, Growth factor, Gene therapy, Bisphosphonates, Hormone replacement therapy, Nitric oxide, and Artificial meniscus.
\end{abstract}

Keywords: Osteoarthritis, Proteinase-activated Receptor-2, BRD4, Novel and Potential therapies.

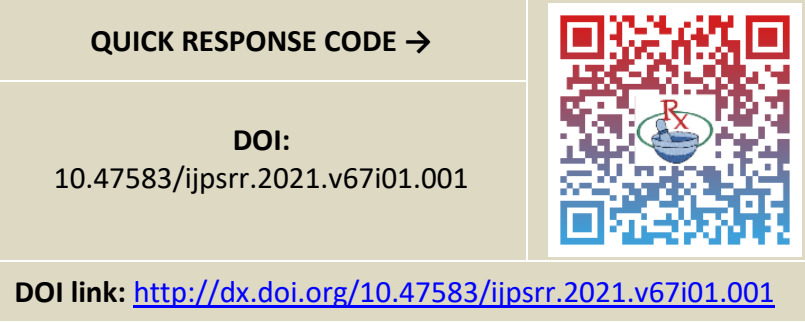

\section{INTRODUCTION}

$\mathrm{O}$ steoarthritis is a state categorized by the progressive destruction of the cartilage that appearances the knee joints, the subchondral bone surfaces, and synovium; convoyed by pain, mobility muscle smoothness, and decrease in function and the capability to whole actions of daily living. The most generally involved joints are the fingers of the near two ends and the joints of the neck, the joint at the base of the thumbs, lower back and the hip joints. In the world population rapidly increasing fraction of aging people, osteoarthritis is becoming a more important public health difficult. Some form of osteoarthritis will have many people over age 60. Various pharmacological mediators able to stop or relief the short term pain and reverse the progression of physical damage. Recent new chemical entities with the latent to become disease altering osteoarthritis drugs generated by pharmaceutical drug discovery environment. Both European and US regulatory guidelines specify that in order to gain a disease modifying osteoarthritis drugs indication, meet the current regulatory necessities of the clinical development. A new chemical entities can slow down diseases physical progression as measured by joint space narrowing (JSN) on plain X-rays scientific studies need to demonstrate that. For osteoarthritis one of the major risk factor is obesity. Those who are overweight, have legs in dissimilar length or have jobs osteoarthritis risk is greater that result in high level of joints stress ${ }^{1-4}$.

\section{There are two main categories of osteoarthritis:}

Primary: It is also known as idiopathic. Very common, primarily affected the fingers, thumbs, spine, hips, knees, the toes, and generalized.

Secondary: It occurs with a preexisting joints abnormality, including trauma or injury, such as psoriatic, rheumatoid or gout; such as sport related and inflammatory arthritis; infection arthritis; disorders of genetic joint.

\section{Signs and Symptoms of Osteoarthritis}

For many, osteoarthritis pain may become markedly worse over time or with specific activities. Characteristic signs and symptoms of osteoarthritis include:

Stiffness. In the morning, the most pronounced first thing is a joint marker of osteoarthritis stiffness or after a continued period of inactivity (such as sitting in a car or airplane). Within 30 minutes of light activity the stiffness 
generally resolves, through mild movement as the joints "warm up".

Pain. During or after too much movement that is another common symptom of pain in the joint. The pain may be experienced as dull and aching, or sharp. Patients may also feel pain when the joints are moving slightly or at rest, that is the most severe cases of osteoarthritis.

Soreness. With slight pressure or the joint may feel tender to touch.

Inflexibility. In the affected joint loss the full range of motion patients may understand.

Swelling. Due to excess fluid buildup the joint may swell. Clinically referred to as effusion, this type of inflammation. the joint may also feel warm to touch, if the swelling is Spartan.

Grating or creaking. When moving the joint, there might be a feeling of grating or slight grinding as the joint no longer move easily against each other, the shells of the articulating points.

Bone spurs. Sometimes, bone bumps which are points of the bone that grow superficial as a result of the joint friction and dysfunction can be felt under the skin. Bone spurs may also known as osteophytes.

Deformity. Physical deformity may be visible, in some types of osteoarthritis. For example, advanced deterioration of knee cartilage can lead to an outward, or puffy finger joints may result from the friction causes bony enlargements of the finger joints, or bowlegged, curvature of the knee.

\section{Causes of osteoarthritis}

Primary osteoarthritis is mostly associated to aging. There are various causes of osteoarthritis following:

Age : Osteoarthritis generally begins from the late $40 \mathrm{~s}$ ahead. Due to body fluctuations that come with ageing, weight gain, such as weakening muscles and the body fetching less able to restore itself efficiently.

Genders : For maximum joints, osteoarthritis is more severe mutual and more mutual in females.

Obesity : Growing the mechanical stress on the cartilage, obesity is the reasons of osteoarthritis. Due to deposition of crystal in the cartilage can cause osteoarthritis and cartilage degradation. vital Factor in initiating osteoarthritis is being weighty, especially the knee and the hip such as in weight-bearing joints.

Joint injury : It can lead to more severe and earlier osteoarthritis than normal, if you were born with developed or regularities them in childhood.

Genetic reasons: Some persons have genetic in one of the genes responsible for creation cartilage. This can cause osteoarthritis to grow in many joints at an earlier age than common.
Other types of joint disease: The second greatest common type of arthritis to develop osteoarthritis, If people have with rheumatoid or gout arthritis. Such as excess growth hormone or iron overload, developing osteoarthritis rises the chance. The symptoms of osteoarthritis affected by the two reasons, but weather and diet aren't a direct cause it.

Weather: The pain increases when changes occurs in the weather that find many people with osteoarthritis, especially when the atmospheric pressure is dropping for example, just earlier it rains. While the climate may affect the indications of your arthritis, it doesn't cause it.

Diet: Some persons find that certain diets appear to rise or decrease their ache and other signs. However, your weight is more probable than any additional exact dietary features to affect your risk of emerging osteoarthritis.

\section{Target of osteoarthritis}

\section{Proteinase-initiated Receptor-2 Target}

Proteinase-initiated receptor-2 participates in the degradative methods of osteoarthritis. The medial meniscus of the right knee OA was surgically induced by disruption in C57BI/6 wild-type (WT) and PAR-2 KO mice. Duration of the study ( 8 weeks post-surgery) the knee puffiness was measured and histologic valuation of cartilage was done to cellularity, assess structure, matrix staining, and remodeling in the deep zone. To performed the morphometric analysis of subchondral bone. In the inflammatory process to be tangled the proteinaseactivated receptor (PAR), was reported. 7-transmembrane $G$ protein-coupled receptors belong to these receptors and are stimulated through a unique method of proteolytic cleavage. This cleavage needs a serine-dependent protease that sequence of unmasks an N-terminal known as a tethered ligand, another extracellular loop which in turn fixes to the receptor's, hence initiating the receptor's signaling cascade ${ }^{5}$. An irreversible phenomenon is a unique activation method of this receptor ${ }^{6}$. This family is collected of 4 members (PIR-1 to PIR-4) expressed by numerous cell types and implicated in pathological and numerous physiological processes ${ }^{7}$. Recently some members of the PIR family have been shown to be elaborate in inflammatory pathways. In arthritic tissues PAR-1 has been found and also be involved. In human cartilage/chondrocytes, synovial fibroblasts and synovial sheath PAR-2 has been documented of OA pathology $8,9,10,11$, with its appearance levels significantly enlarged in $\mathrm{OA}$ related to normal cells. In OA cartilage, PAR-2 activation has been associated with increased invention of the matrix metalloproteinases (MMP)-1 and MMP-13, and COX-213, well known key mediators of OA pathophysiology. Moreover, PAR-2 was also found to be extant in human subchondral bone osteoblasts and was upregulated in OA12. In these OA cells, PAR-2-specific activation resulted in an upregulation of the level of membranous receptor activator of nuclear factor-kB ligand (RANKL) with no effect on osteoprotegerin production, as well as in an increase in bone receptive activity ${ }^{12}$. 
Investigate the in vivo effect of PAR-2 on the growth of articular lesions. Explored the role of this receptor in PAR2 knockout mice using a surgically induced model of OA. Histologic and morphological were estimated.

Methods: Osteoarthritis was surgically induced by destabilization of the medial meniscus of the right knee in C57BI/6 wild-type (WT) and PAR-2 KO mice. Knee swelling was measured throughout the duration of the study ( 8 weeks post-surgery) and histologic evaluation of cartilage was done to assess structure, cellularity, matrix staining, and remodeling in the deep zone. Morphometric analyze of subchondral bone was also performed.

\section{BRD4 has double effects on the HMGB1 and NF-kB signaling pathways and is a potential therapeutic target}

Osteoarthritis is a very common degenerative disease of age-correlated, causing swelling severe joint pain, and functional impairment. In cell phenotypes changes to refers epigenetic modification that connects chromatin structure and DNA sequence occurs independently modifications with gene expression changes ${ }^{13}$. The Bromo and Extra-Terminal (BET) domain family, that belongs to the epigenetic reader proteins family ${ }^{14}$, is characterized by the presence of two tandem bromodomains and an extraterminal domain, which is signal transduction involves in diverse transcriptional systems as effectors ${ }^{15}$. There are four paralogous genes BRD2 comprises the mammalian BET family (originally named RING3), BRDT, BRD4 (MCAP) and $B R D 3$ (ORFX) ${ }^{16}$. In regulating gene transcription play a crucial role of BET proteins through interactions of epigenetic between acetylated histones and bromodomains during differentiation processes and cellular proliferation ${ }^{15}$. A ubiquitously expressed protein of the BET family expressed of BRD4 that plays a critical role of various types of genes in regulating transcriptional elongation by categorizing $\mathrm{N}$-acetylation of lysine residues on histone tails ${ }^{17}$. In BRD4 associated chromatin many histone marks are detected, signifying that BRD4 links with diverse factors that moderate transcription and chromatin dynamics ${ }^{6}$. Moreover, BRD4 joins in direct directing interactions with transcription factors series of DNAbinding to affect their recruits transcriptional regulatory complexes to chromatin and disease-related functions, predominantly through recruitment of the positive transcription elongation factor P-TEFb ${ }^{18-20}$. Studies have demonstrated that JQ1 plays an vital role in moderating the arthritic inflammation by blocking NF-KB signaling of IKK-dependent pathway initiation in rheumatoid arthritis, which shows that directing epigenetic regulators for example BRD4 might be a prospective therapeutic strategy for inflammatory arthritis, In joint diseases and bone ${ }^{21}$. A current study BET inhibitor, I-BET151, proved that BET inhibition conquers the appearance of matrix-degrading enzymes and inflammatory genes in rheumatoid arthritis synovial fibroblasts ${ }^{22-23}$. OA development several genes have been recognized as drivers ${ }^{24-25}$. High Flexibility Group Box Protein 1 (HMGB1) is an ubiquitous chromatin element extensively expressed in other cells and immune ${ }^{26}$. HMGB1 activates the NF-KB signaling pathway, acting as a pro-inflammatory cytokine itself which is involved in the inflammatory reactions of several diseases 27. Studies have proved that HMGB1 and its receptor, receptor for advanced glycation end products (RAGE), are both significantly increased in synovial and peripheral blood of knee osteoarthritis (KOA) patients 28-30. Additionally, the severity of synovitis related with the HMGB1 stages in synovial fluid, daily activities and pain in KOA patients 38 . NF-KB signaling pathway activity and histopathological grade of cartilage destruction related into HMGB1 31-32. Moreover, the pathogenesis of rheumatoid arthritis (RA) involved in HMGB1 by binding to LPS, yielding a complex that identify initiates an inflammatory cascade and TLRs/RAGE ion synovial fibroblasts that leads to the excretion of chemokines inflammatory cytokines and chemokines, production of tissue-destructive enzymes, and finally RA ${ }^{33-34}$. Despite the relationship between $\mathrm{HMGB1}$ and $\mathrm{OA}$, the transcriptional regulatory mechanism that results in proinflammatory reactions of HMGB1 in OA is still largely unknown. In this study, explored the transcriptional regulation of HMGB1 in OA.

NF-KB signaling is highly activated in OA ${ }^{35-36}$, and BRD4 inhibition shown to be an inhibitor of inflammation in bone diseases. HMGB1 is also a well-conserved and pivotal regulator of the immune responses and swelling of $O A$. The exact mechanisms among BRD4, HMGB1 and NF-kB signaling pathway activation in $\mathrm{OA}$ have not been fully elucidated.

\section{Method}

\section{RNA isolation and real-time PCR}

After treatment, total RNA of articular cartilage samples and sw1353 cells was extracted using Triazole reagent (Invitrogen, CA, USA) giving to the manufacturer's directions. For each sample, 1mg of RNA was reversetranscribed (RT) using MLV reverse transcriptase affording to the instruction manual. The specific transcripts were quantified by quantitative real-time PCR using the SYBR ${ }^{\circledR}$ Premix Dimer Eraser ${ }^{\mathrm{TM}}$ (Perfect Real Time) and analyzed by RT-qPCR in Via ${ }^{\mathrm{TM}} 7$ Real-Time PCR System (Life Technology, USA) according to the manufacturer's instructions. Amplification situations were as follows: 2 min of preincubation at $65^{\circ} \mathrm{C}, 10 \mathrm{~min}$ at $95^{\circ} \mathrm{C}$ for enzyme activation, and 40 cycles of denaturation at $95^{\circ} \mathrm{C}$ for 30 is, annealing at $95^{\circ} \mathrm{C}$ for 5 is, and extension at $65^{\circ} \mathrm{C}$ for 30 is. The mRNA levels of target genes were normalized to the $\beta$-actin mRNA level, and the $2-\Delta \Delta C$ t method was used to assess the relative appearance of different applicant genes.

\section{ELISA}

MMPs and inflammatory cytokines, especially MMP3, MMP9, MMP13, IL- 6 and TNF- $\alpha$, are believed to immediate the progression of OA. The sw1353 cells supernatants from different groups were composed and were analyzed using ELISA kits ( $R$ \& D Systems, Minneapolis, MN, USA) 
according to the manufacturer's instructions. The outcomes are expressed as picograms per milliliter.

\section{Novel hyaluronic acid-chitosan nanoparticles as non-viral gene transport vectors targeting osteoarthritis}

Gene therapy is a auspicious new treatment approach for common joint-illnesses like osteoarthritis. The development of harmless, active, targeted non-viral DNA segment carriers is vital for the clinical achievement of gene therapy. The custom of hybrid hyaluronic acid (HA)/chitosan (CS) nanoparticles as new non-viral gene delivery vectors capable of moving exogenous genes into primary chondrocytes for the treatment of joint diseases. HA/CS plasmid-DNA nanoparticles were produced through the complex coacervation of the cationic polymers with $\mathrm{pEGFP}$. Particle size and zeta potential were related to the weight ratio of CS to $\mathrm{HA}$, where rises in nanoparticle size and reductions in surface charge were detected as $\mathrm{HA}$ content increased. The particle size and the zeta potential varied according to $\mathrm{ph}$. Transfection of prime chondrocytes was done under dissimilar situations to examine variations in the $\mathrm{pH}$ of the transfection medium, different N/P ratios, dissimilar plasmid concentrations, and different molecular weights of chitosan. Transfection efficiency was maximized for a medium $\mathrm{pH}$ of approximately 6.8 , an N/P ratio of 5 , plasmid concentration of $4 \mathrm{~g} / \mathrm{ml}$, and a chitosan molecular weight of $50 \mathrm{kDa}$. The transfection efficiency of HA/CSplasmid nanoparticles was significantly higher than that of CS-plasmid nanoparticles under the same conditions. The normal viability of cells transfected with HA/CS-plasmid nanoparticles was over $90 \%$. These outcomes suggest that HA/CS-plasmid nanoparticles could be an effective nonviral vector suitable for gene transport to chondrocytes.

\section{Method}

\section{Scanning electron microscopy (SEM)}

In solution nanoparticles were dropped onto a silica surface with a thin coating of palladium and gold pre coated. Using a JFD-310 (JEOL, Japan) the nanoparticles were lyophilized prior to micrographs and investigation, were found using a SEM.

\section{Particle size and zeta potential measurements}

Measure the charge and size of the nanoparticles used to a Mastersizer 2000 laser diffractometer (Malvern Instruments, Worcestershire, UK). In distilled water at $25^{\circ} \mathrm{C}$ (pH 5.5) The nanoparticles were analyzed and prepared. In order to find out the effect of $\mathrm{pH}$ on the element size and zeta potential, HA/CS-plasmid nanoparticles prepared with CS:HA weight ratio of $4: 1$, were ready by varying the $\mathrm{pH}$ rate of the nanoparticle solution from 5.5 to 8.0 shortly after preparation.

\section{Cell culture}

Cartilage from rabbit knee joint (from 2 New Zealand rabbits, 3 weeks old,) was surgically isolated and located into PBS. Cartilage parts were treated with $0.25 \%$ trypsin at $37{ }^{\circ} \mathrm{C}$ for $30 \mathrm{~min}$, thoroughly sweep away, and treated with $0.1 \%$ collagenase for $12-16 \mathrm{~h}$ in an incubator at $37 \circ \mathrm{C}$ and $5 \% \mathrm{CO} 2$. Subsequently washing twice with DMEM, the isolated chondrocytes were cultivated in monolayer in intermediate consisting of DMEM supplemented with $10 \%$ FBS, and placed in an incubator at $37{ }^{\circ} \mathrm{C}$ and $5 \% \mathrm{CO} 2$ for $5-$ 7 days.

\section{Statistical analysis}

The statistical significance was studied by single-mode ANOVA and the t-test. All of the measurement data were displayed as means \pm standard error of the mean $\left({ }^{-} x \pm s\right)$ and were derived using the SPSS software package (v.13). Differences were consider to be significant at a level of $\mathrm{p}<0.05$.

\section{Novel therapies}

Detection of the disease magnetic resonance imaging (MRI) is a much complex method ${ }^{37}$. It can visualize soft tissues, irregularities in bone and cartilage, and ${ }^{38}$. It can distinguish lining thickness, fluid volume, and after injection of a contrast agent enhancement of the synovial membrane, which allows recognition of synovitis ${ }^{39}$. It can also distinguish cartilage lesions, such as damage of cartilage thickness and joint damage, in specific with $\mathrm{T} 2$ mapping. Though, due to its high expense routine use is restricted ${ }^{37 .}$

At this time treatments and therapeutic targets, there is no treatment and cure for osteoarthritis options are restricted due to the difficulty of the disease. The final treatment decision for progressive osteoarthritis is whole joint arthroplasty, used if the handling of disease signs is not showing effective ${ }^{40}$. There are various recent treatment choices used for OA are concise below.

\section{Pharmacological therapies}

Treatment mostly focuses on pharmaceutical drugs like opioids, non-steroidal anti-inflammatory drugs (NSAIDS), paracetamol and intra-articular injections for reducing inflammation and pain relief. These types of drugs do not stop damage or inverse to the joint and are connected with substantial adverse effects ${ }^{40}$.

\section{Inflammasome blockers}

In the pathogenesis of osteoarthritis involvement of the NLRP3 inflammasome which is an attractive target for therapy. Various approaches are currently being studied to target several components of the inflammasome directly, or pathways operating downstream or upstream of the inflammasome ${ }^{41}$. Pathways which initiate NLRP3, like $\mathrm{Kp}$ efflux and reactive oxygen species (ROS) group have been measured $^{41}$. NLRP3 is a minor molecule inhibitor, named MCC950, was to avoid adaptor apoptosis linked speck-like protein comprising a calcium pyrophosphate deposition disease (CARD) (ASC) oligomerization and IL-1b excretion $^{42}$. Moreover, blocking IL-1b was earlier exposed to decrease cartilage destruction, thus IL-1 treatments such as canakinumab, anakinra and rilonacept may be valuable ${ }^{43}$. 


\section{Regenerative therapies}

Articular cartilage has a little self-curing capacity, thus reformative therapies are conceivable ${ }^{38}$. Autologous chondrocyte implantation $(\mathrm{ACl})$ is generally used for recompense of articular cartilage with in $\mathrm{OA}$ and includes implantation of chondrocytes into the injured cartilage ${ }^{44}$. Contact of cells to anabolic features such as fibroblast growth factor (FGF)-18 and IGF-1 are of interest to increase cartilage regeneration ${ }^{45}$. Further treatments such as tissue engineering and mesenchymal stem cell (MSC) therapy may be auspicious in the upcoming ${ }^{46,47}$.

\section{Biomarkers of OA}

Via current methods, osteoarthritis is often identified late in the disease progression meaning changeable joint damage will have previously happened. The growth of new biomarkers could allow early detection of disease, categorization of patients according to their prognosis and more effective treatment ${ }^{48}$. The utmost studied biomarkers in osteoarthritis originate from cartilage, bone or synovial membrane (degradation or synthesis) which can be measured in the blood, synovial fluid or urine ${ }^{49}$. Proteases and collagenases degrade joint components, e.g., cartilage, and release these dilapidation products into the synovial fluid, blood and urine allowing their detection ${ }^{50}$. The concentration of these molecules fluctuate conferring to disease progression and severity so can theoretically be used as biomarkers. Though, this could account for discrepancies between studies, depending on the disease stage of patients at the time of sampling ${ }^{51}$. Moreover, these biomarkers may not be specific to osteoarthritis, and may be a result of usual bone and cartilage turnover in the body ${ }^{52}$. Potential biomarkers are further defined in below.

\section{COMP}

Cartilage oligomeric matrix protein (COMP) is a glycoprotein. It is found in high concentrations in cartilage $\mathrm{e}^{53,54}$, and has proven beneficial as a prognostic biomarker of cartilage degeneration for knee osteoarthritis ${ }^{55}$. However, it has been found that COMP is not only produced by cartilage but also synovial fibroblasts and ligament, making it less specific to cartilage degeneration ${ }^{56}$. Serum COMP was suggestively improved in those with knee OA compared to age matched controls indicating increased cartilage turnover ${ }^{57}$. It has been associated with hip related symptoms in the absence of radiographic sign ${ }^{58}$, potentially permitting initial diagnosis before permanent joint damage occurs. The Johnston County OA Project found that serum COMP levels in OA patients were significantly higher than control groups, and established that it can predict disease cruelty and associates with the numeral of joints affected ${ }^{59}$.

\section{CTX-II}

C-terminal telopeptide of type II collagen (CTX-II) is an vital marker of cartilage degradation measured in the urine, serum or synovial fluid ${ }^{50}$. It has been shown to be enlarged in osteoarthritis patients and is related with recognition of osteophytes in osteoarthritic joints during radiographic examination and MRI49. It has also exposed to be increased in synovial fluid before it can be spotted by radiography55. Garnero etal found that enlarged rate of development of joint damage was related with lower baseline levels of serum PIIANP and higher baseline levels of serum CTX-II. Though, measured discretely, the association of baseline levels of CTX-II with disease progression was not significant ${ }^{60}$. This recommends that biomarkers yield well outcomes when used in combination rather than distinctly, and further support the idea of developing a panel of biomarkers for osteoarthritis. Biomarkers of type I and type II collagen turnover were active in monitoring short-term treatment retort, and predicted radiographic progression after 1 year in $88 \%$ of patients. This indicates that these proteins may be active biomarkers in a clinical setting for monitoring arthritis development and treatment. ${ }^{61}$

\section{Mesenchymal stem cell therapy}

The determination of this study was to observe whether MSC transplantation could converse the osteoarthritis progression in the knee joint. Stem cell therapy comprises of stem cell solation from adult tissues, theirs expansion in vitro and transfusion back into the patient. It has been postulated that factors secreted in the micro-environment of injured tissue recruit stem cells to the site of active disease and facilitate their differentiation into desired cells.

MSCs, due to their multilineage potential, immunosuppressive activities, limited immunogenicity and relative ease of growth and expansion in culture for clinical use. Although MSCs were originally believed to be important for hematopoietic stem cell (HSC) existence and function, further studies confirmed their abilities to separate into different types of cells (e.g. osteocytes, chondrocytes and skeletal myocytes, as well as the cells of the nervous system) ${ }^{62,63}$.

Two middle-aged men (55 and 65 years,) and two middle aged woman (57 and 54years,) were designated for the study. They had moderate to severe bilateral knee osteoarthritis (mechanical pain of knees, aggravated with walking or climbing stairs, gelling pain, crepitus, restricted range of motion, limitation of joint motion, epiphyseal bony hypertrophy, and X-ray signs of joint space narrowing and osteophyte formation). They were fully explained about the procedure, and after their signed written consent, they entered the study. The following parameters were checked before MSC replacement and at consecutive controls: pain on VAS, time to walk to produce pain, number of stairs to climb to produce pain, the resting time to induce the gelling pain, the range of motion, the instability (if existing) due to lateral and cruciate ligaments, patellae crepitus, and the presence of synovial fluid. 


\section{Novel treatments for early osteoarthritis of the Knee}

The treatment of osteoarthritis continues to evolve. While partial/total knee replacement remains the cornerstone of treatment of end stage osteoarthritis, there is a huge inhabitants of patients with aching knees and initial arthritis for whom arthroplasty is unsuitable. Weight loss, anti-inflammatory anesthetics, physiotherapy, usage of sticks, and activity modification endure the basis of treatment in this group. Several novel treatment modalities in an attempt to clarify their recent role in the managing of early osteoarthritis of the knee.

\section{Low level laser therapy}

Low level laser therapy (LLLT) is a light basis that creates very clean light, of a single wavelength. The outcome is not thermal, but slightly linked to photochemical responses in the cells. A current meta-analysis revealed that the pooled consequences display no effect of 1 month of LLLT on pain or complete patient-rated assessment of disease activity. Though, three trials showed positive effects on pain relief and three trials found no effect. Lower dosage of LLLT was got as active as higher dosage for dropping pain and improving knee range of motion ${ }^{64}$. There is deficiency of data on how LLLT effectiveness is affected by four important factors: wavelength, treatment period, dosage and site of application over nerves instead of joints.

\section{POTENTIAL THERAPIES FOR THE FUTURE}

\section{Cytokines}

The cytokines IL-1b and TNF a show a main role in the inflammatory procedure related with cartilage damage in osteoarthritis. IL-1b is happed as a precursor protein and must be cleaved in order to be active. The enzyme accountable for the cleavage is IL $1 \mathrm{~b}$ converting enzyme (ICE). An in-vitro study of ICE exposed that its inhibition efficiently decreases the production of the active form of $\mathrm{IL}-1 \mathrm{~b}$ in OA cartilage and synovium ${ }^{65}$. An oral inhibitor of ICE has been shown to be active in reducing osteoarthritis harm in two mouse models ${ }^{66}$. Also, IA injection of IL-1 receptor antagonist (IL-1 Ra) has been exposed to produce pain relief and enhanced function in people ${ }^{67}$.

\section{Growth factors}

In response to wound, chondrocytes synthesis macromolecules to reparation damaged tissue. Growth features like insulin-like growth factor-1 (IGF-1) contribute to this reparation process. A pilot study of the usage of recombinant IGF-1 in patients with severe osteoarthritis initiate no modifications in pain or mobility when related to a control group. As a outcome of high cost and suboptimal delivery systems, these growth factors have not undergone extensive medical testing. However, interest remains, fueled by promising in-vitro outcomes. ${ }^{68}$

\section{Gene therapy}

This includes inherited alteration of chondrocytes and/or synovial cells to enable the production of cytokine receptor antagonists (e.g. IL-1 Ra), thus rendering the cartilage/synovium resilient in vivo to cytokine - induced degradation. Inherited alteration involves transfer of genes using or in vitro strategies. The in vitro methods are complex and include various steps including the removal of synovium from the joint, transfection of the cells by a viral or non-viral gene transference process and reintroduction of the transfected cells into the joint. Though, such reintroduced cells have only a transient effect and may perish before any transgene expression occurs. In vivo strategies meant at genetically enhancing chondrocytes or their progenitors may improve transgene appearance and could serve as a continual cause for cytokine receptor antagonists.

\section{Bisphosphonates}

Bisphosphonates prevent osteoclasts directly, either by growing cellular apoptosis or by disturbing the cell's metabolic activity. In osteoarthritis, they appear to act on subchondral bone, where affected joints have reduced bone mineral density and quality and there is enlarged bone turnover like to that detected in patients with osteoporosis. Primary studies using the bisphosphonate risedronic acid have shown its probable use in dropping joint space narrowing capacities.

\section{Hormone replacement therapy}

Epidemiological studies recommend that postmenopausal women are at increased risk for developing OA. Estrogen may thus play a role in osteoarthritis etiology. No randomized, prospective, controlled trials are presently obtainable to assess the direct impact of HRT on the basic progression of osteoarthritis. Furthermore, HRT is not without risk. HRT cannot be recommended as a treatment for osteoarthritis at the present time.

\section{Matrix metalloproteinase inhibitors}

MMPs are a collection of zinc-reliant on proteolytic enzymes that reduce cartilage matrix macromolecules. After excretion, MMPs are initiated by proteolytic exclusion of their pro peptides. Once initiated, regulation in the extracellular matrix is the role of tissue inhibitors of matrix metalloproteinase inhibitors (TIMPs). Defective regulation of MMPs may have a part in the pathogenesis of osteoarthritis. Clinical trials consuming MMP inhibitors to treat osteoarthritis have frequently come across complications with toxicity and the change of such adverse effects as arthralgia, myalgia and tendonitis. This mandatory patient removal from trials. Antibiotics of the tetracycline class (counting doxycycline and minocycline) have been initiate to inhibit MMP action and have likewise compact the severity of osteoarthritis in animal models. Their clinical practice in reducing the progression of osteoarthritis is being explored.

\section{Nitric oxide}

Extra making of nitric oxide (NO) and its by-products (reactive oxygen species ROS), in response to irritation, are supposed to be involved in the pathogenesis of osteoarthritis. One of the enzymes responsible for its 
fusion is inducible NO synthase. Dropping extra production of NO may alleviate OA signs and halt disease development. Animal studies on therapeutic doses of the inducible NOS inhibitor N-aminoethyl-L-lysine have been exposed to decrease the size I of cartilage lesions and the occurrence of osteophytes in a dose- dependent manner ${ }^{69}$. Also, inducible NOS knock-out mice have been exposed to be resilient to experimental osteoarthritis ${ }^{70}$.

\section{Artificial meniscus}

Initial animal studies and mechanical trials via a polyvinyl alcohol-hydrogel (PVA-H) non-natural meniscus displayed encouraging outcomes ${ }^{71}$. Mechanical trials using a higher water content PVA-H displayed viscoelastic behavior like to that of human meniscus and its frictional factor against natural articular cartilage was also operative. Also, primary outcomes of animal studies recommend it may interruption the onset of osteoarthritis meniscectomy.

\section{CONCLUSION}

Osteoarthritis is a chronic progressive disease that is one of the leading causes of disability among elderly populations throughout the world. It causes pain, disability and impaired movement. While there are several therapies available for symptomatic treatment that mitigate pain, there are no medicines that can reverse or halt the progression of the disease. This pharmaceutical gap must be addressed in order to decrease the burden of $O A$. One major reason for this gap is because there is a lack of effective biomarkers and diagnostics for OA, which makes it difficult to diagnose, track progression of, and monitor improvements in the patient's condition. Future research should be directed at addressing this gap in diagnostics and biomarkers which will improve disease monitoring and allow the development of medicines that can reverse the progression of this high-burden condition.

\section{REFERENCES}

1. Guidance for the industry. Clinical development programs for drugs, devices and biologicals products intended for the treatment of osteoarthritis. US Department of Health and human Services. Food and Drug Administration, Center for Drug Evaluation and Research. July 1999. Available from: ttp://www.fda. gov/cder/guidance/2199dft.htm

2. Points to consider on clinical investigation of medicinal products used in the treatment of osteoarthritis. European Agency for the Evaluation of Medicinal Products. Committee for Proprietary Medicinal Products. July 1998. Available

from: http://www.emea.eu.int/pdfs/human/ewp/078497en.pdf

3. Group for the Respect of Ethics and Excellence in Sciences (GREES). Recommendations ssfor the registration of drugs used in the treatment of osteoarthritis. Ann Rheum Dis 1996;55:552-7.

4. Peterfy CG. Imaging the disease process. Curr Opin Rheumatol 2002;14:590-6.

5. Macfarlane SR, Seatter MJ, Kanke T, Hunter GD, Plevin R. Proteinase-activated receptors. Pharmacol Rev 2001;53:245-82.
6. Trejo J. Protease-activated receptors: new concepts in regulation of $\mathrm{G}$ protein-coupled receptor signaling and trafficking. J Pharmacol Exp Ther 2003;307:437-42.

7. Ossovskaya VS, Bunnett NW. Protease-activated receptors: contribution to physiology and disease. Physiol Rev 2004; $84: 579-621$

8. Xiang $\mathrm{Y}$, Masuko-Hongo $\mathrm{K}$, Sekine $\mathrm{T}$, Nakamura $\mathrm{H}$, Yudoh $\mathrm{K}$, Nishioka $K$, et al. Expression of proteinase-activated receptors (PAR)-2 in articular chondrocytes is modulated by IL-1-beta, TNF-alpha and TGF-beta. Osteoarthritis Cartilage 2006;14:1163-73.

9. Boileau C, Amiable N, Martel-Pelletier J, Fahmi H, Duval N, Pelletier JP. Activation of proteinase-activated receptor 2 in human osteoarthritic cartilage upregulates catabolic and proinflammatory pathways capable of inducing cartilage degradation: a basic sciencestudy. Arthritis Res Ther 2007;9:R121.

10. Pelletier J-P, Boileau C, Mineau F, Geng C, Boily M, MartelPelletier J. Upregulation of proteinase-activated receptor (PAR)-2 in human osteoarthritic tissues: a new pathway for the mediation of joint destruction. Clin Exp Rheumatol 2005;23:755.

11. Abe K, Aslam A, Walls AF, Sato T, Inoue H. Up-regulation of protease-activated receptor- 2 by bFGF in cultured human synovial fibroblasts. Life Sci 2006;79:898-904.

12. Amiable N, Tat SK, Lajeunesse D, Duval N, Pelletier JP, Martel-Pelletier J, et al. Proteinase-activated receptor (PAR)-2 activation impacts bone resorptive properties of human osteoarthritic subchondral bone osteoblasts. Bone 2009;44:1143-50

13. L.P. Webber, V.P. Wagner, M. Curra, P.A. Vargas, L. Meurer, V.C. Carrard, C.H. Squarize, R.M. Castilho, M.D. Martins, Hypoacetylation of acetyl-histone $\mathrm{H} 3$ (H3K9ac) as marker of poor prognosis in oral cancer, Histopathology 2017;71:278-286, http://dx.doi.org/10.1111/his.13218 Epub 2017 May 23.

14. S.J. Hogg, S.J. Vervoort, S. Deswal, C.J. Ott, J. Li, L.A. Cluse, P.A. Beavis, P.K. Darcy, B.P. Martin, A. Spencer, A.K. Traunbauer, I. Sadovnik, K. Bauer, P. Valent, J.E. Bradner, J. Zuber, J. Shortt, R.W. Johnstone, BET-Bromodomain inhibitors engage the host immune system and regulate expression of the immune checkpoint ligand PD-L1, Cell Rep. 2017;18:2162-2174.

15. Y. Taniguchi, The bromodomain and extra-terminal domain (bet) family: functional anatomy of bet paralogous proteins, Int. J. Mol. Sci. 2016;17:11-14.

16. G. Andrieu, A.C. Belkina, G.V. Denis, Clinical trials for BET inhibitors run ahead of the science, Drug Discov. Today Technol. 2016;19:45-50.

17. R. Wang, Q. Li, C.M. Helfer, J. Jiao, J. You, Bromodomain protein Brd4 associated with acetylated chromatin is important for maintenance of higher-order chromatin structure, J. Biol. Chem. 2012;287:10738-10752.

18. S.Y. Wu, A.Y. Lee, H.T. Lai, H. Zhang, C.M. Chiang, Phospho switch triggers Brd4 chromatin binding and activator recruitment for gene-specific targeting, Mol. Cell 2013;49:843-857. 
19. P. Anand, J.D. Brown, C.Y. Lin, J. Qi, R. Zhang, P.C. Artero, M.A. Alaiti, J. Bullard, K. Alazem, K.B. Margulies, T.P. Cappola, M. Lemieux, J. Plutzky, J.E. Bradner, S.M. Haldar, BET bromodomains mediate transcriptional pause release in heart failure, Cell 2013;154:569-582.

20. J. Shi, C.R. Vakoc, The mechanisms behind the therapeutic activity of BET bromodomain inhibition, Mol. Cell 2014;54:728-736.

21. Z. Yang, J.H. Yik, R. Chen, N. He, M.K. Jang, K. Ozato, Q. Zhou, Recruitment of PTEFb for stimulation of transcriptional elongation by the bromodomain protein Brd4, Mol. Cell 2005;19:535-545.

22. Y. Xiao, L. Liang, M. Huang, Q. Qiu, S. Zeng, M. Shi, Y. Zou, Y. Ye, X. Yang, H. Xu, Bromodomain and extra-terminal domain bromodomain inhibition prevents synovial inflammation via blocking IkappaB kinase-dependent NFkappaB activation in rheumatoid fibroblast-like synoviocytes, Rheumatology 2016; 55:173-184.

23. K. Klein, P.A. Kabala, A.M. Grabiec, R.E. Gay, C. Kolling, L.L. Lin, S. Gay, P.P. Tak, R.K. Prinjha, C. Ospelt, K.A. Reedquist, The bromodomain protein inhibitor IBET151 suppresses expression of inflammatory genes and matrix degrading enzymes in rheumatoid arthritis synovial fibroblasts, Ann. Rheum. Dis. 2016;75:422-429.

24. E. Barrett, S. Brothers, C. Wahlestedt, E. Beurel, I-BET151 selectively regulates IL-6 production, Biochim. Biophys. Acta 2014;1824:1549-1555.

25. P. Lepetsos, A.G. Papavassiliou, ROS/oxidative stress signaling in osteoarthritis, Biochim. Biophys. Acta 2016;1862:576-591.

26. H. Fang, F. Zhang, F. Li, H. Shi, L. Ma, M. Du, Y. You, R. Qiu, H. Nie, L. Shen, Y. Bai, J. Lyu, Mitochondrial DNA haplogroups modify the risk of osteoarthritis by altering mitochondrial function and intracellular mitochondrial signals, Biochim. Biophys. Acta 2016; 1862:829-836.

27. H. Yang, M. Ochani, J. Li, X. Qiang, M. Tanovic, H.E. Harris, S.M. Susarla, L. Ulloa, H. Wang, R. DiRaimo, C.J. Czura, H. Wang, J. Roth, H.S. Warren, M.P. Fink, M.J. Fenton, U. Andersson, K.J. Tracey, Reversing established sepsis with antagonists of endogenous high-mobility group box 1 , Proc. Natl. Acad. Sci. U. S. A. 2004;101:296-301.

28. U. Andersson, H. Erlandsson-Harris, HMGB1 is a potent trigger of arthritis, J. Intern. Med. 2004;255:344-350.

29. M. Nefla, D. Holzinger, F. Berenbaum, C. Jacques, The danger from within: alarmins in arthritis, Nat. Rev. Rheumatol. 2016;12:669-683.

30. Tao, J. Song, T. Lan, X. Xu, P. Kvietys, R. Kao, C. Martin, T. Rui, Cardiomyocytefibroblast interaction contributes to diabetic cardiomyopathy in mice: role of HMGB1/TLR4/IL33 axis, Biochim. Biophys. Acta 2015;1852:2075 2085.

31. X. Ke, G. Jin, Y. Yang, X. Cao, R. Fang, X. Feng, B. Lei, Synovial fluid HMGB-1 levels are associated with osteoarthritis severity, Clin. Lab. 2015;61:809-818.

32. X.H. Sun, Y. Liu, Y. Han, J. Wang, Expression and significance of high-mobility group protein B1 (HMGB1) and the receptor for advanced glycation end-product (RAGE) in knee osteoarthritis, Med. Sci. Monit. 2016;22:2105-2112.
33. C. Terada, A. Yoshida, Y. Nasu, S. Mori, Y. Tomono, M. Tanaka, H.K. Takahashi, M. Nishibori, T. Ozaki, K. Nishida, Gene expression and localization of high-mobility group box chromosomal protein-1 (HMGB-1)in human osteoarthritic cartilage, Acta Med. Okayama 2011;65:369377.

34. Y. Qin, Y. Chen, W. Wang, Z. Wang, G. Tang, P. Zhang, Z. He, Y. Liu, S.M. Dai, Q. Shen, HMGB1-LPS complex promotes transformation of osteoarthritis synovial fibroblasts to a rheumatoid arthritis synovial fibroblast-like phenotype, Cell Death Dis. 2014; 5:e1077.

35. N. Sapojnikova, T. Kartvelishvili, N. Asatiani, V. Zinkevich, I. Kalandadze, D. Gugutsidze, R. Shakarishvili, A. Tsiskaridze, Correlation between MMP-9 and extracellular cytokine HMGB1 in prediction of human ischemic stroke outcome, Biochim. Biophys. Acta 2014;1842:1379-1384.

36. E. Olivotto, M. Otero, K.B. Marcu, M.B. Goldring, Pathophysiology of osteoarthritis: canonical NFkappaB/IKKbeta-dependent and kinase-independent effects of IKKalpha in cartilage degradation and chondrocyte differentiation, RMD Open 2015; 1:e000061.

37. S. Rigoglou, A.G. Papavassiliou, The NF-kappaB signalling pathway in osteoarthritis, Int. J. Biochem. Cell Biol. 2013;45:2580-2584.

38. J.E. Bolden, N. Tasdemir, L.E. Dow, J.H. van Es, J.E. Wilkinson, Z. Zhao, H. Clevers, S.W. Lowe, Inducible in vivo silencing of Brd4 identifies potential toxicities of sustained BET protein inhibition, Cell Rep. 2014; 8:1919-1929.

39. S. Meng, L. Zhang, Y. Tang, Q. Tu, L. Zheng, L. Yu, D. Murray, J. Cheng, S.H. Kim, X. Zhou, J. Chen, BET inhibitor JQ1 blocks inflammation and bone destruction, J. Dent. Res. 2014;93:657-662.

40. Nguyen LT, Sharma AR, Chakraborty C, Saibaba B, Ahn ME, Lee SS. Review of prospects of biological fluid biomarkers in osteoarthritis. Int J Mol Sci 2017;18:601.

41. Menashe L, Hirko K, Losina E, Kloppenburg M, Zhang W, Li $L$, et al. The diagnostic performance of MRI in osteoarthritis: a systematic review and meta-analysis. Osteoarthritis Cartilage 2012;20:13e21.

42. Wenham $C$, Conaghan $P$. The role of synovitis in osteoarthritis. Ther Adv Musculoskelet Dis 2010;2:349e59.

43. Zhang $W$, Ouyang $H$, Dass $C R$, Xu J. Current research on pharmacologic and regenerative therapies for osteoarthritis. Bone Res 2016;4:15040.

44. Di Virgilio F. The therapeutic potential of modifying inflammasomes and NOD-like receptors. Pharmacol Rev 2013;65: 872e905.

45. Coll RC, Robertson AAB, Chae JJ, Higgins SC, Munoz-Planillo $\mathrm{R}$, Inserra $\mathrm{MC}$, et al. A small-molecule inhibitor of the NLRP3 inflammasome for the treatment of diseases. Nat Med 2015;21:248e55.

46. Dinarello CA, Simon A, van der Meer JWM. Treating inflammation by blocking interleukin-1 in a broad spectrum of diseases. Nat Rev Drug Discov 2012;11:633e52.

47. Tuan RS. A second-generation autologous chondrocyte implantation approach to the treatment of focal articular cartilage defects. Arthritis Res Ther 2007;9:109. 
48. Goldring $M$, Berenbaum F. Emerging targets in osteoarthritis therapy. Curr Opin Pharmacol 2015;22:51e63.

49. Freitag J, Bates D, Boyd R, Shah K, Barnard A, Huguenin L, et al. Mesenchymal stem cell therapy in the treatment of osteoarthritis: reparative pathways, safety and efficacy e a review. BMC Musculoskelet Disord 2016;17:230.

50. Daher RJ, Chahine NO, Greenberg AS, Sgaglione NA, Grande DA. New methods to treat and diagnose cartilage degeneration. Nat Rev Rheumatol 2009;5:599e607.

51. Kraus VB, Burnett B, Coindreau J, Cottrell S, Eyre D, Gendreau M, et al. Application of biomarkers in the development of drugs intended for the treatment of osteoarthritis. Osteoarthritis Cartilage 2011;19:515e42.

52. Lotz M, Martel-Pelletier J, Christiansen C, Brandi M-L, Bruyere $O$, Chapurlat $R$, et al. Value of biomarkers in osteoarthritis: current status and perspectives. Ann Rheum Dis 2013;72:1756e63.

53. Park YM, Kim SJ, Lee KJ, Yang SS, Min BH. Detection of CTXII in serum and urine to diagnose osteoarthritis by using a fluoromicrobeads guiding chip. Biosens Bioelectron 2015;67:192e9.

54. King KB, Lindsey $C T$, Dunn TC, Ries MD, Steinbach LS, Majumdar S. A study of the relationship between molecular biomarkers of joint degeneration and the magnetic resonancemeasured characteristics of cartilage in 16 symptomatic knees. Magn Reson Imaging 2004;22:1117e23.

55. Garnero P, Rousseau JC, Delmas PD. Molecular basis and clinical use of biochemical markers of bone, cartilage, and synovium in joint diseases. Arthritis Rheum 2000;43:953e68.

56. Attur M, Krasnokutsky-Samuels S, Samuels J, Abramson S. Prognostic biomarkers in osteoarthritis. Curr Opin Rheumatol 2013;25:136e44.

57. Garnero P, Piperno M, Gineyts E, Christgau S, Delmas PD, Vignon E. Cross sectional evaluation of biochemical markers of bone, cartilage, and synovial tissue metabolism in patients with knee osteoarthritis: relations with disease activity and joint damage. Ann Rheum Dis 2001;60:619e26.

58. Rousseau J, Delmas P. Biological markers in osteoarthritis. Nat Clin Pract Rheumatol 2007;3:346e56.

59. Clark AG, Jordan JM, Vilim V, Renner JB, Dragomir AD, Luta $G$, et al. Serum cartilage oligomeric matrix protein reflects osteoarthritis presence and severity. Arthritis Rheum 1999;42:2356e64.

60. Garnero P, Ayral X, Rousseau JC, Christgau S, Sandell LJ, Dougados $M$, et al. Uncoupling of type II collagen synthesis and degradation predicts progression of joint damage in patients with knee osteoarthritis. Arthritis Rheum 2002; 46:2613e24.

61. Mullan RH, Matthews C, Bresnihan B, FitzGerald O, King L, Poole AR, et al. Early changes in serum type II collagen biomarkers predict radiographic progression at one year in inflammatory arthritis patients after biologic therapy. Arthritis Rheum 2007;56:291.

62. Friedenstein AJ, chailakhyan RK, Latsinik NV, pnasyuk AS, keiliss-Borok IV; Stromal cells responsible for transferring the microenvironment of the hemopoietic tissues. Cloning in vitro and re-transplantation in vivo. Transplantation 1974;17:331-40.

63. D, Schwarz EJ, Prockop DJ, Black IB; Adult rat and human bone marrow stromal cells differentiation into neurons. J Neurosci Res 2000;61:364-70.

64. Brosseau L, Gam A, Harman K, et al. Low level laser therapy (Classes I, II and III) for treating osteoarthritis. Cochrane Database Syst Rev 2004;19(3):CD 002046.

65. Saha N, Moldovan F, Tardif G, et al. Interleukin-1 betaconverting enzyme/caspace-1 in human osteosrthritic tissues: localisation and role in the maturation of interleukin- 1beta and interleukin-18. Arthritis Rheum 1999;42(8):1577-87.

66. Rudolphi K, Gerwin N, et al. Pralnacasan, an inhibitor of interleukin-1 beta conerting enzyme, reduces joint damage in two murine models of osteoarthritis. Osteoarthritis Cartilage 2003;11(10):738-46.

67. Goupille P, Giraubeau B, et al. Safety and efficacy of intraarticular injection of IL-1ra in patients with painful osteoarthritis of the knee: a multicenter, double-blind study [abstract 1822]. Arthritis Rheum 2003;48(Suppl):S696

68. Haupt JL, Frisbie DD, Mcllwraith CW, et al. Dual transduction of insulin-like growth factor-I and interleukin1 receptor antagonist protein controls cartilage degradation in an osteoarthritic culture model. J Orthop Res 2005;23(1): 118-26.

69. Pelletier JP, Jovanovic DV, Fernandes JC, et al. Reduced progression of experimental osteoarthritis in vivo by selective inhibition of inducible nitric oxide synthase. Arthritis Rheum 1998;41(7):1275-86.

70. van den Berg WB, van de Loo F, Joosten LA, et al. Animal models of arthritis in NOS2-deficient mice. Osteoarthritis Cartilage 1999;7(4):413-5.

71. Kobayashi M, Chang YS, Oka M. A two year in vivo study of polyvinyl alcohol-hydrogel (PVA-H) artificial meniscus. Biomaterials 2005;26(16):3243-8.

Source of Support: None declared.

Conflict of Interest: None declared.

For any question relates to this article, please reach us at: editor@globalresearchonline.net

New manuscripts for publication can be submitted at: submit@globalresearchonline.net and submit_ijpsrr@rediffmail.com 